\title{
5.3
}

\section{COMPARISON OF MEASUREMENTS FROM SATELLITE RADIATION BUDGET INSTRUMENTS}

\author{
G. Louis Smith ${ }^{1}$, Z. Peter Szewczyk ${ }^{2}$, David A. Rutan ${ }^{3}$ and Robert B. Lee, III \\ 1 National Institute for Aerospace, Hampton, Virginia \\ 2 Science Application International Corp., Hampton, Virginia \\ 3. Analytical Services and Materials, Inc., Hampton, Virginia \\ 4. Atmospheric Sciences Division, NASA Langley Research Center, Hampton, Virginia
}

\begin{abstract}
Successive radiometers have been flown on spacecraft for measurement of the radiation budget of the Earth and to date have provided data sets which overlap in time over a 25 -year period. In this paper we compile these results in order to demonstrate the traceability of calibration of satellite radiation budget instruments over these two decades. From this compilation the differences can be computed for any two instruments listed.
\end{abstract}

\section{INTRODUCTION}

The Earth's atmosphere and oceans constitute a heat engine for which the heat source is the Sun's radiation and the heat sink is the radiation emitted from the Earth. Thus, our weather and climate are strongly coupled to the incoming and outgoing radiation, which varies on many scales in time and space. Because of the importance of radiation, since 1978 successive radiometers have been flown on spacecraft for measurement of the radiation budget of the Earth and to date have provided data sets which overlap in time over a 25-year period and are useful for climate research. Together these data sets cover two cycles of a decadal oscillation. Figure 1 is a time line showing the periods for which these radiometers provided data.

Although these instruments have all been calibrated with great care, inevitably there are differences between the instruments and their results. The precision of the data is typically much higher than the absolute accuracy. If one

Corresponding author address: G. Louis Smith, National Institute of Aerospace, Mail Stop 420, Langley Research Centre, Hampton, Virginia 23681; e-mail: g.l.smith@larc.nasa.gov compares results from overlapping data sets for a given quantity, often small corresponding temporal variations can be discerned in both data sets, demonstrating the high precision, but the two time histories are displaced, showing the relative accuracy of the two data sets, e.g. Wielicki et al. (2002). A number of studies have compared measurements between pairs of radiometers in order to establish these differences between pairs of radiometers. The vertical lines between pairs of instruments in fig. 1 indicate the comparisons which have been made. In this paper we compile these results in order to demonstrate the traceability of calibration of satellite radiation budget instruments over the last quarter-century. In this compilation the differences can be computed for any two instruments listed here. The fundamental question considered in this paper is the bias of the radiometers. In all cases the bias discussed is the bias of one instrument relative to another. No consideration is given to absolute bias, which cannot be determined.

Comparison of higher level data products, e.g. gridded fluxes, introduce differences to a number of effects. The computation of fluxes from radiance measurements requires use of a model to account for anisotropy of reflected solar radiation and outgoing longwave radiation, thereby introducing errors into the flux computation which are typically greater than the errors in the measurement. Differences of equator-crossing time of the spacecraft produce the variations of flux from one data set to another, even though the data processing may attempt to minimize this effect. For this reason, direct comparison of measurements which are coincident in time and space is preferable. These measurements are compared and differences are noted so that the user of multiple data sets can take into account these differences in his work. There is no way to establish the absolute accuracy of any instrument in space, thus no attempt is made here to adjust the data sets from each instrument to form a self- 
consistent data set for the total period. In this paper radiation budget instruments are enumerated, then the results of comparison studies are compiled. Given biases between a minimal set of pairs of instruments, the biases between any pair of instruments are computed. Similarly, the accuracies with which the biases are known, as defined by the standard deviations of the biases, are computed in like manner. This information is useful to an investigator who is using multiple data sets in order to understand any differences between the data sets.

\section{RADIATION BUDGET INSTRUMENTS AND DATA SETS}

There are three types of satellite radiometers for measurement of the radiation budget of the Earth: scanning radiometers, non-scanning radiometers and detector arrays. Smith (1998) reviewed Earth radiation budget data sets as of 1997. The Earth radiation budget radiometers are briefly discussed, first the scanner, then the nonscanners, or wide-field-of-view (WFOV) radiometers, and finally the Geostationary Earth Radiation Budget (GERB) radiometer, which is the first radiation budget instrument to apply a detector array.

Table 1 lists the radiation budget scanning radiometers which have flown to date, along with the dates at which the data records began and ended and the type of orbits in which they operated. Table 2 contains similar information for WFOV radiometers. The first instrument designed for broadband radiation budget measurements was the Earth Radiation Budget instrument (W. L. Smith et al., 1977; Jacobowitz et al., 1984; Kyle et al., 1993) which contained both a scanning radiometer and non-scanning wide field-of view radiometers. The ERB had limited in-flight calibration capability, so that it was necessary to use Earth scenes to infer the calibrations as the channels degraded in orbit. On subsequent instruments, improved in-flight calibration devices were included. The Earth Radiation Budget Experiment followed (Barkstrom and Smith, 1986), with scanning and WFOV radiometers (Kopia, 186; Luther, 1986) on the NOAA9 and NOAA 10 and on the dedicated Earth Radiation Budget Satellite (ERBS). The ScaRaB 1 (Kandel et al., 1994; Kandel et al., 1998) flew aboard the Meteor 3/7 and the ScaRaB 2 aboard the Resurs 1/4. The Clouds and the Earth Radiant Energy System (CERES) proto-flight model (Smith et al., 1998a \& b) flew on the Tropical Rainfall Measuring Mission (TRMM) and Flight Models 1 and 2 (FM 1 and 2) aboard the Terra spacecraft (Priestley et al., 2000) and Flight Models 3 and 4 aboard the Aqua spacecraft (Priestley et al., 2003; Spence et al., 2003). As of this writing, the CERES instruments aboard the Terra and Aqua are still operating well.

The Geostationary Earth Radiation Budget instrument (Harries and Crommelynck, 1999; Harries et al., 2004; Mossavati et al., 1998), presently in orbit, is the first Earth radiation budget instrument to use a detector array. The first GERB instrument to fly is aboard the MeteoSat Second Generation-1 spacecraft (MSG1 ), which has recently become operational as Meteosat-8, and plans are for GERB instruments to fly on the next four Meteosat spacecraft. The detector array consists of 256 detectors, which view the Earth through a telescope. The views alternate, with no filter so as to measure total radiance and with a quartz filter so as to measure SW radiance. In spacecraft centered coordinates, each detector views at a constant elevation angle, corresponding roughly to a line of constant Earth latitude. As the spacecraft rotates, each detector scans across the Earth to generate an image of total and SW radiances.

\section{METHODS OF COMPARISON}

There are four cases: WFOV to WFOV, WFOV to scanner, scanner to scanner and scanner to array. This paper will not consider the WFOV to WOFV case.

The ERB WFOV aboard the Nimbus 7 provided a 12-year data set and overlapped in time with the ERBE instruments. Kyle et al. (1990) compared ERB WFOV with ERBS WFOV at TOA by use of shape factors. This approach has the problem that the altitude of the ERB WFOV aboard the Nimbus 7 spacecraft was 955 $\mathrm{km}$ and thus had a much larger field of view (FOV) than did the ERBS WFOV at an altitude of 620 $\mathrm{km}$. As a consequence, the comparison of the measurements shows a large amount of scatter and the slope of the correlation line between the two instruments shows a larger variation of the ERBS flux than for the Nimbus 7 ERB, because of the FOV difference. This case will not be considered further.

All of the radiometers considered in this comparison use one channel to measure total radiation (radiance for scanners, flux for WFOV), 
nominally $0.2 \mu$ to $30.0 \mu$ or greater, and a similar channel with a quartz filter to measure SW radiation. Nighttime LW is derived from the total channel only, The total channel has the flattest spectral response of the channels, thus the LW night is the most reliable radiance or flux measurement. The spectral resonse of the SW channel has more variability due to the addition of the quartz filters, so that it has greater error than the LW night. The LW day is the total minus the SW, thus has all of the errors of both channels.

The spectral responses of the channels are not constant over the spectral range of the channel, so that the measurement is of a spectrally filtered radiance or flux, from which the "unfiltered" radiance or flux must be computed. This unfiltered radiance or flux is the quantity of interest and is the quantity which is reported. Also, because the spectral responses of even similar channels differ, it is pointless to compare the filtered quantities.

\subsection{WFOV to Scanner Comparison method}

The technique of intercomparison of WFOV and scanner measurements was developed by Green et al. (1990). The WFOV measurement is the integral of the radiances impinging on the instrument, weighted by the cosine of the nadir angle:

$$
m(\boldsymbol{x})=\int_{F O V} L(\boldsymbol{x}, \boldsymbol{n}) \cos \alpha d
$$

where $\boldsymbol{x}$ is the location of the WFOV radiometer and $\boldsymbol{n}$ is the unit vector in the direction of the radiance. The scanning radiometer measures radiances from each point in a swath centered about the ground track of the spacecraft.

The radiances from the scanner $L(\boldsymbol{x}, \boldsymbol{n})$ differ by those in the WFOV measurement due to the anisotropy of the field, which for OLR field is described by limb- darkening functions. It is assumed that the OLR field is constant in time during the several minutes required for the spacecraft to traverse the distance needed for the scanner swath to cover the WFOV field-of-view. For the reflected solar radiation, the solar zenith angle will change across the FOV during this time. This change is included in the computation.

Green et al. (1990) applied this method to compare the ERBS WFOV and scanner and their results are summarized in table 3 . Subsequently Bess et al. (1999) applied the software developed by Green to compare the ERBS WFOV radiometer with the $\mathrm{ScaRaB} 1$ radiometer and then Rutan et al. (1999) used the method to compare ERBS WFOV with the CERES/TRMM scanner, for which the results are included in table 3 also. These results were all given as the difference between the flux as measured by the WFOV and that computed from the scanning radiometer radiances by use of equations (1) through (3). The parameter of interest is the flux at the top of the atmosphere (TOA), thus the flux differences have been computed at TOA by use of the shape factor, which for the ERBS WFOV radiometer is 0.85 .

\subsection{Scanner to scanner comparison method}

The best way to compare scanning radiometer measurements is to use radiometers which are co-located in space and time and viewing in the same direction, so that they both observe the radiance from the same scene in the same direction. The CERES radiometer can be programmed to rotate the scan plane in azimuth as desired. Haeffelin et al. (2001) used this capability to align the scan plane of the CERES/TRMM with the scan plane of the ScaRaB 2 instrument at the point of the intersection of their orbits. The resulting data set provided a number of scenes which were viewed from the same direction by both scanners. Due to the differences between the point response functions of different instruments and the differing positions of the measurement locations, the measurements are compiled in grid boxes of latitude and longitude. The differences between the shortwave and longwave radiances are shown in table 4 . The radiance differences are multiplied by $p$ to express the differences in terms of TOA fluxes. The same technique was used by Szewczyk et al. (2002) to compare radiances of the CERES/TRMM with those of the CERES FM1 and FM-2, aboard the Terra spacecraft.

Szewczyk et al. (2004) used the Haeffelin method to compare radiances of the CERES FM1 with those of the CERES FM-4, aboard the Aqua spacecraft. These spacecraft are in Sunsynchronous orbits such that the Terra spacecraft crosses the Equator at 10:30 hours and the Aqua crosses the Equator at 13:30 hours. As a consequence, their orbits cross at noon at $70^{\circ} \mathrm{N}$ and at midnight at $70^{\circ} \mathrm{S}$. The best time to compare shortwave radiances is near the June solstice, when the insolation at $70^{\circ} \mathrm{N}$ is 
maximum. The FM-1 and FM-4 scanners were operated with scan planes rotated so as to scan in east-west directions in June and July of 2002, 2003 and 2004 both near $70^{\circ} \mathrm{N}$ and $70^{\circ} \mathrm{S}$. The northern case provided shortwave and daytime longwave comparison data and the southern case gave nighttime longwave comparison data. These results are listed in table 4 also

\subsection{Scanner to array comparison}

The GERB detector array consists of 256 detectors, each of which is used to measure shortwave radiance and total radiance, whence longwave radiance. In order to provide sufficient CERES measurements with which to make comparisons, the scan plane of the CERES FM-1 was oriented such that the GERB was in the scan plane (Smith et al., 2002). Thus, during each scan the view direction lines up with that of the GERB for some Earth scene. As the Terra moves along its orbit over the MeteoSat sector, the scanner ws programmed so as to rotate in azimuth to maintain this alignment. This operation was performed near the solstices in June 2003 and December 2003 and June 2004, so $\infty$ to maximize the insolation in the Northern and Southern Hemispheres. These data are currently being used to validate the GERB data and will be reported in due course.

\section{COMPILATION OF COMPARISONS}

Comparisons for WFOV-to-scanner measurements and for scanner-to-scanner measurements from existing studies are first compiled. Next the biases of fluxes at TOA are computed for any pair of instruments. Each case includes SW, LW night and LW day.

Instruments continually degrade while they are in orbit. Thus, comparisons are only valid for the time interval over which comparison due to instrument changes. Calibrations attempt to remove these effects, but the differences are sufficiently small in many cases that they are comparable to the accuracy of the calibration changes applied.

\subsection{WFOV-scanner comparisons}

Table 3 lists the results from studies comparing WFOV flux measurements with those from scanners by use of the Green method. The ERBS WFOV was used to compare with the
ERBS scanner (Green et al., 1990), the ScaRaB1 scanner (Bess et al., 1999) and the CERES/TRMM scanner (Rutan et al., 2001). The bias is the mean of the set of pairs of WFOV measurement minus the scanner calculation. The resulting bias at TOA is computed by dividing the bias at the WFOV radiometer by the shape factor, which is 0.85 for the ERBS WFOV. The accuracy of the computed bias of the measurements is taken to be the standard deviation of the sample mean and is listed at the WFOV altitude and also computed at TOA by use of the shape factor.

\subsection{Scanner-scanner comparisons}

Table 4 lists the results of investigations of comparisons of scanning radiometer measurements. These include the CERES/TRMM with the ScaRaB2 (Haeffellin et al., 2001) and FM 1 (Szewczyk, 2002), and the FM 1 with the FM 4 (Szewczyk et al., 2004) and the accuracies of the biases in terms of the standard deviations of the sample mean of the bias. The resulting bias of the computed TOA flux is computed by multiplying the bias of radiances by $\pi$; likewise the standard deviation of the computed bias of flux at TOA is computed from the standard deviation of radiances by multiplying by $\pi$.

Spence et al. $(2002,2003)$ compared the FM1 and -2 on the Terra and the FM-3 and -4 on the Aqua spacecraft. Spence provided updated biases and standard deviations of these comparisons based on edition 2 for tables 5, 6 and 7 in a private communication.

\subsection{Extension of bias results to all pairs of radiometers}

The comparisons of SW fluxes from various radiometers is shown by fig. 2 , which is a bar chart with horizontal distance indicating bias. The origin is defined by the ERBS WFOV. Vertical lines connect radiometers to other radiometers with which direct comparison measurements have been made, indicated by the nodes, at which point the horizontal line indicates the bias of one radiometer relative to the other, e.g. from table 3 or 4 , and thus indicate traceability of comparisons between radiometers. For any pairs of instruments whose measurements were not directly compared, the bias is the horizontal distance between the end points for each 
instrument. The standard deviation of the error of the relative biases is computed by following the relations in like manner. An inferred bias is the sum of two biases, thus the variance of the inferred bias is the sum of the variances of the two biases.

The relative biases for all pairs of radiometers discussed are given in tables 5, 6 and 7 for SW, LW night and LW day, with the accuracies computed for these biases. The biases are listed in the half of the table above the diagonal and the standard deviation of the bias is listed below the diagonal for any pair of radiometers. The bias for a pair of radiometers is for the TOA flux from the radiometer designated by the row minus the TOA flux from the radiometer designated by the column. The biases and standard deviations compiled from previous investigations, listed in tables 3 and 4 and other comparisons discussed above, are indicated by bold fonts and those computed from these are indicated by regular weight fonts.

The compiled data are a minimal set in that there is only one path connecting each of the radiometers. A second path would be expected to produce somewhat different results, thereby giving a validation of the biases and of the computed standard deviations. For example, the NOAA 10 scanner measurements could be compared directly with the ERBS WFOV measurrements.

\section{DISCUSSION AND FUTURE WORK}

The next radiation budget instrument to be flown on a low Earth orbiting spacecaft is the Earth Radiation Budget Sensor, which is to fly on the NPOESS spacecraft in 2001. This is 12 years after the launch of Terra, with CERES FM-1 and 2 and nine years after the launch of Aqua, with FM-3 and -4 . There is a high probability that after that time, the current CERES instruments will have failed, leaving a gap in the two decade record which we have developed. The most pressing need for radiation budget is to fly the CERES FM-5 instrument in time to prevent a gap in the radiation budget data record. Preferably the FM-5 would fly on a mission with other instruments such that the data sets together would provide insight into weather and climate processes.

Comparisons are needed of the NOAA 9 ERBE scanner and WFOV and the NOAA 10 WFOV measurements with those of the ERBS. Also, the Nimbus 7 ERB WFOV measurements should be compared with those from the ERBS scanner.

In the near future, the comparison of CERES and GERB should be completed. With the validation of GERB done, these products will provide information about the energetics of atmospheric processes on a daily scale.

\section{ACKNOWLEDGEMENTS}

This work was supported by the Clouds and Earth Radiant Energy System (CERES) program of the Earth Science Enterprise of NASA through Langley Research Center by contracts to the National Institute of Aerospace, SAIC and Analytical Sciences and Materials, Inc.

\section{REFERENCES}

Barkstrom, B. R. and G. L. Smith, The Earth Radiation Budget Experiment: Science and Implementation, Rev. of Geophys., 24, 379390 (1986).

Bess, T. D., G. L. Smith, K. A. Bush and D. A. Rutan, 1999: "Intercomparison of ScaRaB and ERBS monthly mean radiation fluxes," Proc. 10th Conf. Atmos. Rad., 60-63, American Met. Soc.

Green, R. N., F. B. House, P. W. Stackhouse, X. Wu, S. A. Ackermann, W. L. Smith and M. J. Johnson, 1990: Intercomparison of scanner and nonscanner measurements for the Earth radiation budget experiment (ERBE), J. Geophys. Res., 95, 11,785-11,798.

Harries, J. E. et al., 2004: The Geostationary Earth Radiation Budget (GERB) Project, submitted to Bull. Amer. Met. Soc.

Harries, J. E. and D. Crommelynck, 1999: The Geostationary Earth Radiation Budget experiment on MSG-1 and its potential application. Adv. in Space Res., 24, 915-919.

Haeffelin, M., B. A. Wielicki, J. P. Duvel, K. Prestley and M. Viollier, 2001: Inter-calibration of CERES and ScaRaB Earth radiation budget data sets using temporally and spatially collocated radiance measurements, Geophys. Res. Let. 28, 167-170.

Jacobowitz, H., H. V. Soule, H. L. Kyle, F. B. House and the Nimbus-7 ERB experiment team, 1984: The Earth radiation budget (ERB) experiment : An overview, J. Geophys. Res., 89, 5021 - 5038 (1984).

Kandel, R. S., J. L. Monge, M. Viollier, L.A. Pakhomov, V. I. Adasko, R. G. Reitenbach 
and E. Raschke, 194: The SCARAB Project: Earth Radiation Budget observations from the METEOR satellites, Adv. Space Res., 14, 147-154 (1994).

Kandel, R., M. Viollier, L. A. Pakhomov, V. A. Golovko, E. Raschke, R. Stuhlmann, and the international ScaRaB Scientific Working Group (ISSWG), 1998: The ScaRaB Earth radiation budget data set, Bull. Amer. Met. Soc., 79, 765-783.

Kopia, L. P., 1986: Earth Radiation Budget Experiment scanner instrument, Rev. Geophys., 24, 400-406.

Kyle, H. L. and Coauthors, 1993: "The Nimbus Earth radiation budget (ERB) experiment: 1975 to 1992", Bull. Am. Met Soc., 74, 815830.

Luther, M. R., J. E. Cooper and G. R. Taylor, 1986: The Earth Radiation Budget Experiment non- scanning instrument, Rev. of Geophys., 24, 391-399.

Mossavati, R., Harries, J. E., Kellock, S. J., Wrigley, R. T., Mueller, J. and Fox, N. P., 1998: Radiometric calibration of the GERB instrument. Metrologia, 35(4), 603-607.

Priestley, K. J., R. B. Lee III, B. R. Barkstrom, S. Thomas, R. S. Wilson, A. Al-Hajjah, J. Paden, D. K. Pandey, P. L. Spence, and G. L. Smith, 2000: "Post-launch radiometric performance validation of CERES Flight Models 1 and 2 located on NASA's Terra Spacecraft," Proc. SPIE, 4135-04.

Priestley, K. J., S. Thomas, P. J. Spence, Z. P. Szewczyk, E. A. Kizer, D. Walikanainen, A. Al-Hajjah and R. S. Wilson, 2003: "A comprehensive radiometric protocol for the CERES Earth radiation budget climate record sensors," Proc. SPIE: Earth Observing Systems VIII, v. 5151, 282-287.

Rutan, D. A., G. L. Smith, T. P. Charlock and R. N. Green, 1999: "Early Intercomparison of CERES and ERBE Results," Proc. Third Symp. Integrated Observing Systems, 209212, American Met. Soc.

Rutan, D. A.,, G. L. Smith, R. B. Lee III, 2001 "Intercomparison of CERES Scanning and ERBS WFOV Non-Scanning Radiometers," Proc. Conf. Sat. Met., American Met. Soc.

Smith, G. L., 1998: "Critical Overview of Radiation Budget Estimates from Satellites," Adv. Space Res., 24, 887-495,

Smith, G. L., R. B. Lee III, B. R. Barkstrom, B. A. Wielicki, K. J. Priestley, S. Thomas, J. Paden, R. S. Wilson, D. K. Pandey and K. L.
Thornhill, 1998: Overview of CERES Sensors and In- flight Performance, Optical Sci., Eng. \& Instrum., Proc., SPIE, v. 3439.

Smith, G. I., B. R. Barkstrom, R. B. Lee III, B. A. Wielicki, R. N. Green, T. P. Charlock, P. Minnis, B. A. Baum, D. F. Young and K. J. Priestley, 1998: "The Clouds and Earth Radiant System Instrument aboard the Tropical Rain Measurement Mission (CERES/TRMM): Early Results," Proc. Symp. Sat. Remote Sensing of Clouds and Atmos III, 246-255.

Smith, G.L., Z.P. Szewczyk, P.E. Mlynzak, R.B. Lee III, B.A. Wielicki, K.J. Priestley, J. Harries, S. Dewitte, and Nicolas Clerbaux, 2003: Method for comparison of GERB and CERES radiances, Proc., 10-th Internat. Symp. SPIE, Barcelona.

Smith, W. L., J. Hickey, H. B. Howell, H. Jacobowitz, D. T. Hilleary and A. J. Drummond, 1977: Nimbus 6 Earth radiation budget experiment, Appl. Opt., 16, 306 - 318.

Spence, P. L., K. J. Priestley, and S. Thomas, 2002: "In-flight stability analyses applied to the Clouds and the Earth's Radiant Energy System scanning thermistor bolometer instruments on the Terra satellite", Proceedings of SPIE, Earth Observing Systems VII.

Spence P., K. Priestley, E. Kizer, D. Walikainen, S. Thomas, 2003: "Three-channel intercomparison and direct comparison on-orbit stability analyses as applied to the CERES instruments on the Terra and Aqua satellites", SPIE Annual Meeting, San Diego, CA.

Szewczyk, Z. P., 2002: Comparison of short-wave radiances measured by CERES instruments operating on TRMM and Terra satellites, Proc. Rem. Sens. Of Clouds and the Atmos VII, 4882-76, SPIE, Agia Pelagia, Crete.

Szewczyk, Z.P., G.L. Smith, K. J. Priestley, 2004: Comparison of CERES instruments aboard the Terra and Aqua satellites, J. Geophys. Res., accepted.

Wielicki, B. A., B. R. Barkstrom, E. F. Harrison, R. B. Lee III, G. L. Smith and J. E. Cooper, 1996: Clouds and the Earth's Radiant Energy System (CERES): An Earth Observing System Experiment, Bull. Amer. Met. Soc., 77, 853-868.

Wielicki B. A., Wong TM, Allan RP, Slingo A, Kiehl JT, Soden BJ, Gordon CT, Miller AJ, Yang SK, Randall DA, Robertson F, Susskind J, Jacobowitz H, 2002: Evidence for large 
decadal variability in the tropical mean radiative energy budget. Science, 295, 841844

Table 1: Scanning Radiometers

\begin{tabular}{|l|l|l|l|}
\hline Instrument & Data Start & Data End & $\begin{array}{c}\text { Equator } \\
\text { Crossing }\end{array}$ \\
\hline \hline $\begin{array}{l}\text { ERB/ } \\
\text { Nimbus 6 }\end{array}$ & July 1975 & Aug 1975 & $12: 00$ \\
\hline $\begin{array}{l}\text { ERB/ } \\
\text { Nimbus 7 }\end{array}$ & Nov. 1978 & May 1980 & $12: 00$ \\
\hline $\begin{array}{l}\text { ERBE/ } \\
\text { ERBS }\end{array}$ & Nov. 1984 & Jan. 1989 & $\begin{array}{l}72 \text { day } \\
\text { precession }\end{array}$ \\
\hline $\begin{array}{l}\text { ERBE/ } \\
\text { NOAA 9 }\end{array}$ & Jan. 1985 & Jan. 1987 & 09:00 \\
\hline $\begin{array}{l}\text { ERBE/ } \\
\text { NOAA 10 }\end{array}$ & Oct. 1986 & May 1989 & $15: 00$ \\
\hline $\begin{array}{l}\text { ScaRaB-1 } \\
\text { Car. 1994 }\end{array}$ & Feb. 1995 & $\begin{array}{l}7 \text { month } \\
\text { precession }\end{array}$ \\
\hline $\begin{array}{l}\text { CERES/ } \\
\text { TRMM }\end{array}$ & Dec. 1997 & Sept. 1998 & $\begin{array}{l}35 \text { days } \\
\text { precession }\end{array}$ \\
\hline $\begin{array}{l}\text { ScaRaB-2 } \\
\text { Scan. 1998 }\end{array}$ & Mar. 1999 & \\
\hline $\begin{array}{l}\text { CERES/ } \\
\text { Terra/FM-1 }\end{array}$ & Jan. 2000 & - & $22: 30$ \\
\hline $\begin{array}{l}\text { CERES/ } \\
\text { Terra/FM-2 }\end{array}$ & Jan. 2000 & - & $22: 30$ \\
\hline $\begin{array}{l}\text { CERES/ } \\
\text { Aqua/FM-3 }\end{array}$ & June 2002 & - & $13: 30$ \\
\hline $\begin{array}{l}\text { CERES/ } \\
\text { Aqua/FM-4 }\end{array}$ & June 2002 & - & $13: 30$ \\
\hline $\begin{array}{l}\text { CERES/ } \\
\text { FM-5 }\end{array}$ & - & & \\
\hline
\end{tabular}

Table 2: Non-scanning Radiometers

\begin{tabular}{|l|l|l|l|}
\hline Instrument & Data Start & Data End & $\begin{array}{l}\text { Equator } \\
\text { Crossing }\end{array}$ \\
\hline \hline $\begin{array}{l}\text { ERB/ } \\
\text { Nimbus 6 }\end{array}$ & July 1975 & June 1978 & $12: 00$ \\
\hline $\begin{array}{l}\text { ERB/ } \\
\text { Nimbus 7 }\end{array}$ & Nov. 1978 & Oct. 1987 & $12: 00$ \\
\hline $\begin{array}{l}\text { ERBE/ } \\
\text { ERBS }\end{array}$ & Nov. 1984 & Oct. 1999 & $\begin{array}{l}72 \text { day } \\
\text { precession }\end{array}$ \\
\hline $\begin{array}{l}\text { ERBE/ } \\
\text { NOAA 9 }\end{array}$ & Jan. 1985 & July 1990 & 07:30 \\
\hline $\begin{array}{l}\text { ERBE/ } \\
\text { NOAA 10 }\end{array}$ & Oct. 1986 & Oct. 1994 & $15: 00$ \\
\hline
\end{tabular}

Table 3: ERBS WFOV-Scanner comparisons,

\begin{tabular}{|c|c|c|c|c|}
\hline Scanner & $\begin{array}{c}\Delta \text { flux } \\
\text { at S/C, }\end{array}$ & $\begin{array}{c}\Delta \text { flux } \\
\text { at TOA }\end{array}$ & $\begin{array}{c}\sigma \text { Flux } \\
\text { at S/C }\end{array}$ & $\begin{array}{c}\sigma \text { Flux } \\
\text { at TOA }\end{array}$ \\
\hline \hline ERBS & & & & \\
\hline SW & 5.0 & 5.9 & 3.8 & 4.5 \\
\hline LW night & 3.0 & 3.5 & 1.1 & 1.3 \\
\hline LW day & -5.0 & -5.9 & 1.4 & 1.6 \\
\hline ScaRab 1 & & & & \\
\hline SW & 0.8 & 0.9 & 5.5 & 6.5 \\
\hline LW night & 0.6 & 0.7 & 1.9 & 2.2 \\
\hline LW day & -3.8 & -4.5 & 2.2 & 2.6 \\
\hline CERES TRMM & & & & \\
\hline SW & -0.6 & -0.7 & 10.8 & 12.7 \\
\hline LW night & -0.2 & -0.2 & 2.9 & 3.4 \\
\hline LW day & -5.8 & -6.8 & 3.5 & 4.1 \\
\hline
\end{tabular}


Table 4: Scanner-to-scanner comparisons

\begin{tabular}{|c|c|c|c|c|}
\hline Instrument Pair & $\begin{array}{c}\Delta \\
\text { radiance } \\
\text { W-m } \\
\mathrm{sr}^{-1}\end{array}$ & $\begin{array}{l}\Delta \text { flux, } \\
\text { W-m }\end{array}$ & $\begin{array}{c}\sigma \\
\text { radiance } \\
\text { W-m }-\mathrm{m}^{-2} \\
\mathrm{sr}^{-1}\end{array}$ & $\begin{array}{l}\sigma \text { flux, } \\
W-m^{-2}\end{array}$ \\
\hline \multicolumn{5}{|l|}{$\begin{array}{l}\text { NOAA } 10- \\
\text { ERBS }\end{array}$} \\
\hline SW & 0.4 & 1.1 & 3.7 & 11.7 \\
\hline LW night & -0.1 & -0.4 & 0.5 & 1.6 \\
\hline LW day & 0.2 & 0.5 & 0.6 & 1.8 \\
\hline \multicolumn{5}{|l|}{$\begin{array}{l}\text { CERES TRMM- } \\
\text { ScaRaB } 2 \\
\end{array}$} \\
\hline SW & -1.1 & -3.5 & 2.2 & 6.9 \\
\hline LW night & 0.5 & 1.6 & 0.4 & 1.3 \\
\hline LW day & 0.7 & 2.2 & 0.5 & 1.6 \\
\hline \multicolumn{5}{|l|}{$\begin{array}{l}\text { CERES TRMM - } \\
\text { FM } 1\end{array}$} \\
\hline SW & -0.6 & -0.2 & 3.0 & 9.4 \\
\hline LW night & 0.7 & 2.2 & 0.4 & 1.3 \\
\hline LW day & 0.7 & 2.3 & 0.5 & 1.6 \\
\hline \multicolumn{5}{|l|}{ FM 1 - FM 4} \\
\hline SW & 0.3 & 1.0 & 0.7 & 2.2 \\
\hline LW night & -0.1 & -0.2 & 0.1 & 0.3 \\
\hline LW day & -0.4 & -1.4 & 0.2 & 0.6 \\
\hline
\end{tabular}

Table 5: Shortwave relative flux biases at TOA (above diagonal) and standard deviations (below diagonal), $\mathrm{W}-\mathrm{m}-2$

\begin{tabular}{|c|c|c|c|c|c|c|c|c|c|c|}
\hline & $\begin{array}{c}\text { ERBS } \\
\text { SC }\end{array}$ & $\begin{array}{l}\text { ERBS } \\
\text { NS }\end{array}$ & $\begin{array}{l}\text { NOAA } \\
10 \mathrm{SC}\end{array}$ & $\begin{array}{c}S c a R a B \\
1\end{array}$ & $\begin{array}{l}\text { CERES } \\
\text { TRMMM }\end{array}$ & $\begin{array}{c}\mathrm{ScaR} a \mathrm{~B} \\
2\end{array}$ & $\begin{array}{l}\text { CERES } \\
\text { FM-1 }\end{array}$ & $\begin{array}{l}\text { CERES } \\
\text { FM-2 }\end{array}$ & $\begin{array}{l}\text { CERES } \\
\text { FM-3 }\end{array}$ & $\begin{array}{c}\text { CERES } \\
\text { FM-4 }\end{array}$ \\
\hline ERBS SC & - & -59 & -1.1 & -50 & -6.6 & -10.1 & -6.8 & -6.4 & -5.7 & 5.8 \\
\hline ERBSNS & 45 & - & -4.8 & 0.9 & -0.7 & 4.2 & 0.9 & -0.5 & 0.2 & 0.1 \\
\hline NOA_A $10 \mathrm{SC}$ & 11.7 & & - & -3.8 & -5.4 & -89 & -5.6 & -4.2 & -4.5 & -3.7 \\
\hline ScaRaB 1 & 79 & 6.5 & & - & -1.6 & -5.1 & -1.1 & 1.4 & -0.7 & -0.8 \\
\hline CERESITRMM & 13.5 & 12.7 & 17.9 & 14.3 & - & -3.5 & -0.2 & 0.2 & 0.9 & 0.8 \\
\hline ScaRaB 2 & 15.1 & 14.4 & 19.2 & 15.8 & 6.9 & - & 3.3 & 4.7 & 4.4 & 4.3 \\
\hline CERES FMI-1 & 16.4 & 15.8 & 20.2 & 17.1 & 9.4 & 11.7 & - & 0.4 & 1.1 & 1.0 \\
\hline CERES FM-2 & 16.4 & 15.8 & 20.2 & 17.1 & 9.4 & 11.7 & 0.6 & - & 0.7 & 0.6 \\
\hline CERES FM-3 & 166 & 16.0 & 20.3 & 17.2 & 96 & 11.9 & 2.2 & 2.3 & - & -0.1 \\
\hline CERES FML 4 & 166 & 16.0 & 20.3 & 17.2 & 96 & 11.9 & 22 & 2.3 & 0.2 & - \\
\hline
\end{tabular}


Table 6: Longwave, nighr, relative flux biases at TOA (above diagonal) and standard deviations (below diagonal), $\mathrm{W}-\mathrm{m}^{-2}$.

\begin{tabular}{|c|c|c|c|c|c|c|c|c|c|c|}
\hline & $\begin{array}{c}\text { ERBS } \\
\mathrm{Sc}\end{array}$ & $\begin{array}{c}\text { ERBS } \\
\text { NS }\end{array}$ & $\begin{array}{l}\text { NOAA } \\
10 \mathrm{SC}\end{array}$ & $\begin{array}{c}\text { ScaRaB } \\
1\end{array}$ & $\begin{array}{c}\text { CEFES } \\
l \\
\text { TRMM }\end{array}$ & $\begin{array}{c}\mathrm{ScaR} a \mathrm{~B} \\
2\end{array}$ & $\begin{array}{c}\text { CERES } \\
\text { FM-1 }\end{array}$ & $\begin{array}{c}\text { CERES } \\
\text { FM-2 }\end{array}$ & $\begin{array}{c}\text { CERES } \\
\text { FM-3 }\end{array}$ & $\begin{array}{l}\text { CERES } \\
\text { FM-4 }\end{array}$ \\
\hline ERBS SC & - & -3.5 & 0.4 & 4.2 & 3.3 & 49 & 6.5 & 4.7 & 5.3 & 6.3 \\
\hline ERBS NS & 1.3 & - & -3.1 & 0.7 & -0.2 & 1.4 & -20 & 1.2 & 1.8 & -1.8 \\
\hline NOAd $10 \mathrm{SC}$ & 16 & & - & 3.8 & 29 & 4.7 & 5.1 & 4.3 & 4.9 & 4.9 \\
\hline ScaRaB 1 & 26 & 2.2 & 3.1 & - & -09 & 0.7 & 1.3 & 0.5 & 1.1 & 1.1 \\
\hline CERESITRMMI & 3.6 & 3.4 & 4.0 & 4.1 & - & 1.6 & 22 & 1.4 & 20 & 20 \\
\hline ScaRaB 2 & 39 & 3.6 & 4.2 & 4.3 & 1.3 & - & 0.6 & 0.4 & 0.2 & 0.4 \\
\hline CERES FM-1 & 39 & 3.6 & 4.2 & 4.3 & 13 & 2.1 & - & -0.8 & -0.4 & -0.2 \\
\hline CERES FM-2 & 39 & 3.6 & 4.2 & 4.3 & 1.3 & 2.1 & 0.2 & - & 0.6 & 0.6 \\
\hline CERES FM- 3 & 39 & 3.6 & 4.2 & 4.3 & 1.3 & 2.1 & 0.3 & 0.4 & - & 0.0 \\
\hline CERES FM-4 & 3.9 & 3.6 & 4.2 & 4.3 & 1.3 & 2.1 & 0.3 & 0.4 & 0.0 & - \\
\hline
\end{tabular}

Table 7: Longwave, Day, relative flux biases at TOA (above diagonal) and standard deviations (below diagonal), $\mathrm{W}-\mathrm{m}-2$

\begin{tabular}{|c|c|c|c|c|c|c|c|c|c|c|}
\hline & $\begin{array}{c}\text { ERES } \\
S C\end{array}$ & $\begin{array}{l}\text { ERRS } \\
\text { NS }\end{array}$ & $\begin{array}{l}\text { NOAd } \\
\text { 10SC }\end{array}$ & $\underset{1}{S \mathrm{CaRaB}}$ & $\begin{array}{l}\text { CERES } \\
\text { TRMM }\end{array}$ & $\underset{2}{S_{C a R a B}}$ & $\begin{array}{l}\text { CERES } \\
\text { FM-1 }\end{array}$ & $\begin{array}{c}\text { CERES } \\
\text { FM-2 }\end{array}$ & $\begin{array}{c}\text { CERES } \\
\text { FM-3 }\end{array}$ & $\begin{array}{l}\text { CERES } \\
\text { FM-4 }\end{array}$ \\
\hline ERBS SC & - & 5.9 & -0.5 & 1.4 & -0.9 & 1.3 & 1.4 & 1.3 & 0.4 & 0.0 \\
\hline ERBS NS & 1.6 & - & -5.4 & -4.5 & -6.8 & -4.6 & -4.5 & -4.6 & -5.5 & -5.9 \\
\hline NOAd $10 \mathrm{SC}$ & 18 & & - & 0.9 & -1.4 & 0.8 & 0.9 & 0.8 & -0.1 & -0.5 \\
\hline $\mathrm{ScaRaB}_{1}$ & 2.9 & 2.6 & 3.4 & - & -2.3 & -0.1 & 0.0 & -0.1 & -1.0 & -1.4 \\
\hline CERESTRMM & 4.4 & 4.1 & 4.8 & 4.7 & - & 2.2 & 2.3 & 2.2 & 1.3 & 0.9 \\
\hline ScaRaB 2 & 4.7 & 4.4 & 5.0 & 5.2 & 1.6 & - & 0.1 & 0.0 & -1.1 & -1.3 \\
\hline CERES FM-1 & 4.7 & 4.4 & 5.0 & 5.0 & 1.6 & 2.3 & - & -0.1 & 1.2 & -1.4 \\
\hline CERES FM-2 & 4.7 & 4.4 & 5.1 & 5,0 & 1.7 & 2.3 & 0.5 & - & 0.8 & 0.6 \\
\hline CERES FM-3 & 4.7 & 4.5 & 5.1 & 5.1 & 1.7 & 2.4 & 0.7 & 0.8 & - & -0.4 \\
\hline CERES FM-4 & 4.7 & 4.5 & 5.1 & 5.0 & 1.7 & 2.3 & 0.6 & 0.6 & 0.3 & - \\
\hline
\end{tabular}




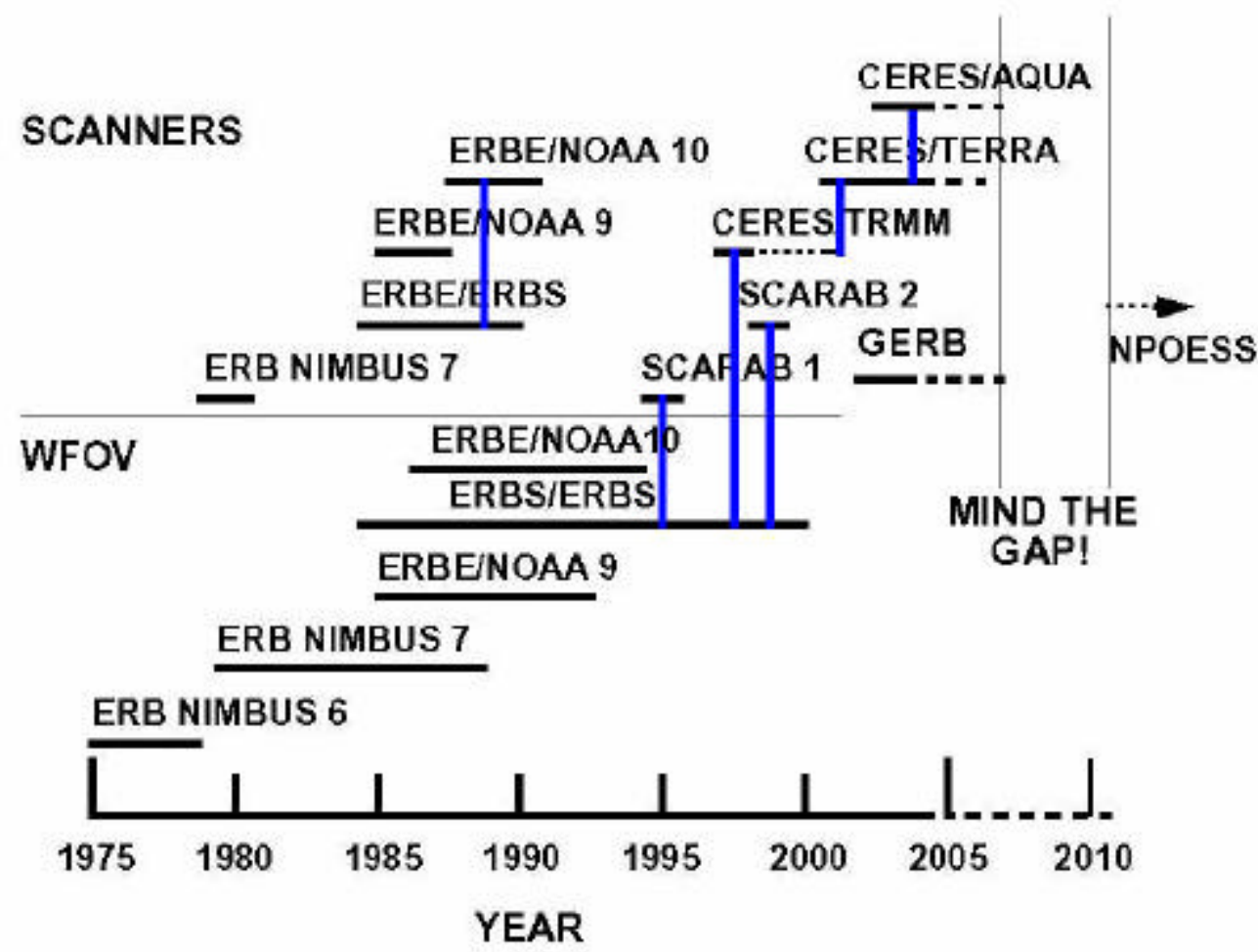

Flgure 1. Time line of Earth radiation budget data sets.

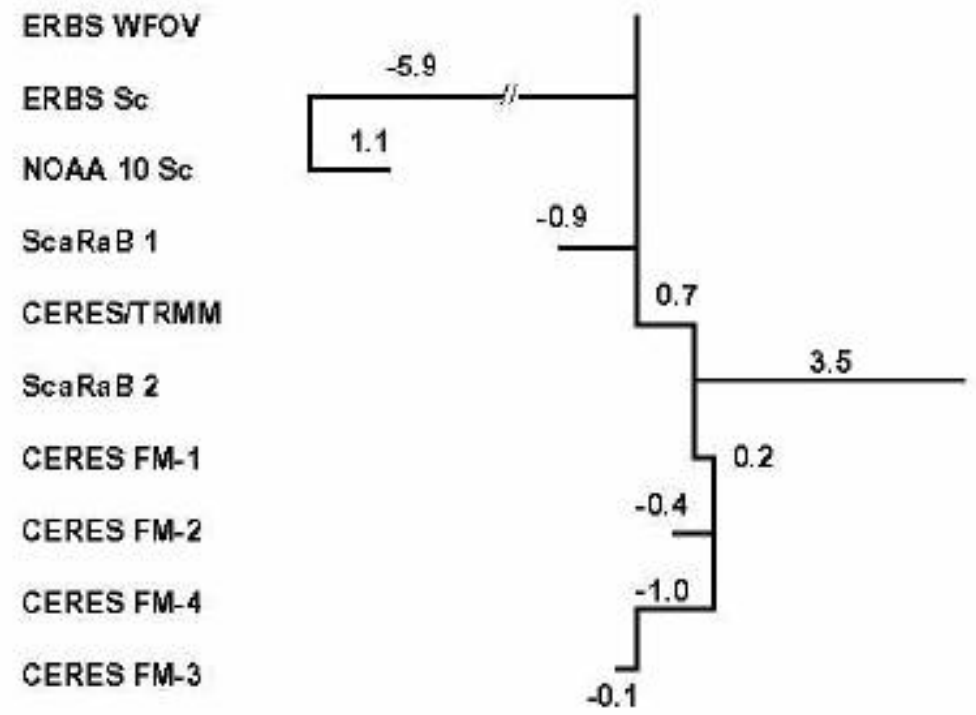

Figure 2: Chart of traceability of biases between radiometers 